\title{
Kontrol Navigasi Robot Beroda pada Kontes Robot Pemadam Api Indonesia (KRPAl) Menggunakan Fuzzy Logic
}

\author{
${ }^{1}$ Sunu Jatmika, ${ }^{2}$ Jamil Wahyu \\ ${ }^{1}$ Sekolah Tinggi Manajemen Informatika \& Komputer ASIA Malang \\ 2 Sekolah Tinggi Manajemen Informatika \& Komputer ASIA Malang \\ ${ }^{1}$ sunu.srg@gmail.com,2jamilwahyu87@yahoo.com
}

\begin{abstract}
Abstrak
Sistem Pakar atau expert system adalah cabang dari Al (artificial intelegence) yang mulai diperkenalkan pada tahun 70-an. Dalam kaitannya dengan sistem kontrol, sistem pakar dapat diimplementasikan sebagai salah satu teknik kontrol cerdas. Selain sistem pakar teknik kontrol cerdas lain terkenal adalah fuzzy logic.

Teknologi robot sampai saat ini udah mengalami perkembangan yang sangat pesat baik robot untuk game, edukasi, industri dan untuk kompetisi. Salah satu robot yang belakangan ini banyak menarik para peneliti untuk dikembangkan adalah robot mobil/beroda baik untuk industri atau dunia pendidikan. Penelitian ini bertujuan untuk meningkatkan keakuratan navigasi robot beroda agar mampu menjelajah arena dengan mencari titik api di tiap ruangan untuk dipadamkan dengan cepat. Gerakan robot dipengaruhi beberapa item yang memiliki nilai ketidakpastian seperti penempatan sensor, kekuatan motor dan bentuk mekanik robot untuk itu diperlukan metode untuk meningkatkan navigasi yaitu fuzzy logic dengan prinsip kerjanya nilai input akan dikelompokkan dalam himpunan fuzzy.

Kata Kunci : Sistem Pakar, Artificial Integelgence, Fuzzy Logic , Robot Mobile, Navigasi
\end{abstract}

\section{Pendahuluan}

Artificial Intelegence atau kecerdasan buatan merupakan bidang ilmu yang mengalamani inovasi sangat cepat. Bidang ilmu ini lebih ditekankan pada perancangan otomatisasi tingkah laku cerdas dalam sistem kecerdasan komputer. Beberapa bidang ilmu yang menggunakan kecerdasan buatan salah satunya adalah sistem pakar. Dalam kaitannya dengan sistem kontrol, sistem pakar dapat diimplementasikan sebagai salah satu teknik kontrol cerdas. Selain sistem pakar teknik kontrol cerdas lain terkenal adalah fuzzy logic.Teknologi robot sampai saat ini udah mengalami perkembangan yang sangat pesat baik robot untuk game, edukasi, industri dan untuk kompetisi. Salah satu robot yang belakangan ini banyak menarik para peneliti untuk dikembangkan adalah robot mobil/beroda baik untuk industri atau dunia pendidikan. Tahun 2004 diadakan kontes $\mathrm{KRCl}$ awal pertama kali oleh DP2M Dikti yang diikuti perguruan tinggi secara regional dan nasional, salah satunya adalah Kontes Robot Pemadam Api Indonesia (KRPAl) untuk kategori robot beroda. Dalam kontes tersebut robot menjelajah arena dengan mencari titik api di tiap ruangan untuk dipadamkan maka diperlukan kecepatan dan keakuratan robot, untuk itu factor navigasi sebagai kunci utama.

Navigasi robot dipengaruhi beberapa parameter yang tidak liner seperti berat robot, penempatan sensor, kecepatan perputaran motor dan bentuk mekanik robot. Agar navigasi bisa dikontrol diperlukan penerapan fuzzy logic supaya robot bisa memiliki kecepatan dan keakuratan dalam kontes.

\section{Tinjauan Pustaka}

Fuzzy Logic adalah suatu pengetahuan yang membuat komputer dapat meniru kecerdasan manusia sehingga diharapkan komputer dapat melakukan hal-hal yang apabila dikerjakan manusia memerlukan kecerdasan yang dapat diimplementasikan ke suatu perangkat, salah satunya robot. Fuzzy logic diperkenalkan oleh Prof. Lotfi Zadeh dari Universitas California di Berkeley pada tahun 1965. Fuzy logic diterapkan dalam bidang kontrol oleh E.H. Mamdani dan sejak itu perkembangan fuzzy sangat pesat pada tahun 1980-an Jepang mulai membangun produk-produk kebutuhan rumah tangga berbasis fuzzy logic. Fuzzy logic pada umumnya diterapkan pada masalah-masalah yang mengandung unsur ketidakpastian dan ketidaktepatan. Sebagai contoh jarak "dekat" didefiniskan di bawah $5 \mathrm{~cm}$. Bagaimana dengan jarak 4,999 atau 4,5 apakah masih dikatakan dekat ?. Prinsip kerja dari fuzzy logic yang pertama adalah Fuzzification Secara garis besar tahap pertama ini berfungsi untuk mengubah suatu besaran analog menjadi fuzzy input. Penjelasan proses fuzzyfikasi yaitu suatu besaran analog dimasukkan sebagai input (crisp input), lalu input tersebut dimasukkan pada batas scope/domain sehingga input tersebut dapat dinyatakan dengan label (dingin, panas, cepat, 
lambat, dll) dari membership function. Membership function ini biasanya dinamakan membership function input.

Dari membership function inilah kita dapat mengetahui berapa degree of membership function-nya (derajat keanggotaan). Salah satu cara yang dapat digunakan untuk mendapatkan nilai keanggotaan adalah dengan melalui pendekatan fungsi. Pada kasus ini digunakan representasi kurva berbentuk bahu.

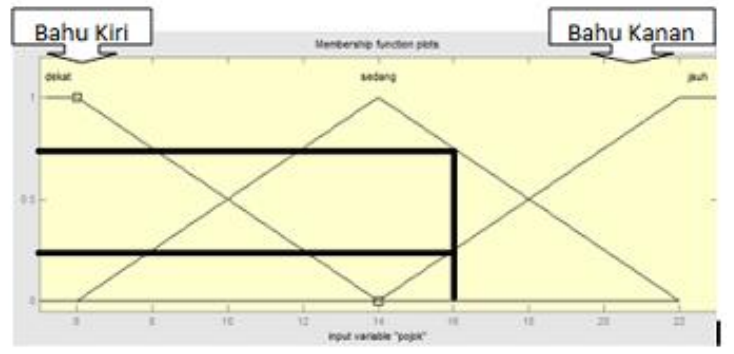

Gambar 1 kurva bahu

Adapun penyelesaian dalam mencari fungsi keanggotaan setiap representasi sebagai berikut: Fungsi keanggotaan representasi turun,

$$
\mu[x]=\left\{\begin{array}{cc}
(b-x) /(b-a) & , a \leq x \leq b \\
0 ; & x \geq b
\end{array}\right.
$$

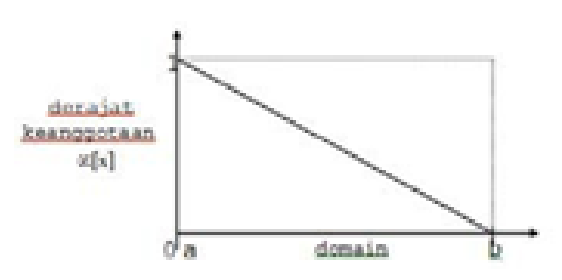

Gambar 2 fungsi keanggotaan represntasi turun

Fungsi keanggotaan representasi naik.

$$
\pi[x]=\left\{\begin{array}{c}
0 ; x \leq \text { a atau } x \geq c \\
(x-a) /(b-a) ; a \leq x \leq b \\
(b-x) /(c-b) ; b \leq x \leq c
\end{array}\right.
$$

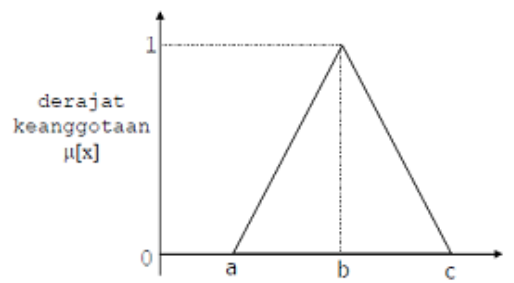

Gambar 4 fungsi keanggotaan kurva segitiga
Kedua Evaluasi Rule Proses ini berfungsi untuk melakukan perhitungan dalam mencari suatu nilai fuzzy output dari fuzzy input. Prosesnya adalah sebagai berikut: suatu nilai fuzzy input yang diperoleh dari proses fuzzifikasi kemudian dimasukkan kedalam sebuah rule yang telah ditentukan sebelumnya untuk dijadikan sebuah fuzzy output. Pada sistem ini rule yang digunakan adalah menggunakan suatu hubungan sebab akibat (If-then). Jika didalam aturan tersebut terdapat lebih dari satu buah kondisi maka akan digunakan suatu implikasi atau pemotongan output dari fungsi keanggotaan. Tiap-tiap aturan (proposisi) pada basis pengetahuan fuzzy akan berhubungan dengan suatu relasi fuzzy. Untuk kasus ini yang akan digunakan dalam implikasi adalah fungsi min. Sedangkan untuk komposisi aturan akan digunakan fungsi max, atau mengambil nilai maksimum dari kumpulan nilai aturan yang sudah didapatkan. Ketiga Defuzzifikasi merupakan proses pengubahan variabel berbentuk fuzzy tersebut menjadi datadata pasti (crisp) yang dapat dikirimkan ke peralatan pengendalian.

\section{Rancangan Penelitian}

Dalam melakukan penelitian ada beberapa tahapan yang harus dilakukan yaitu :

\subsection{Arsitektur Fuzzy Logic}

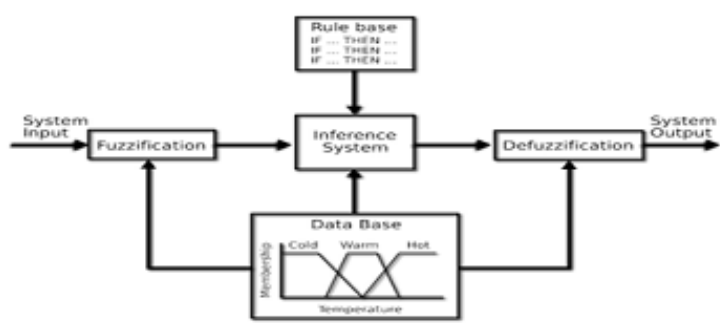

Gambar 5 arsitektur fuzzy logiz

Ada tiga proses utama dalam penerapan fuzzy logic dalam perangkat yaitu fuzzifikasi, evaluasi rule, dan defuzzifikasi.

\subsection{Diagram Blok}

Diagram blok merupakan gambaran dasar dari rangkaian robot yang akan dirancang baik dari input, proses, ataupun output dari robot. Setiap diagram blok mempunyai fungsi masing-masing. 


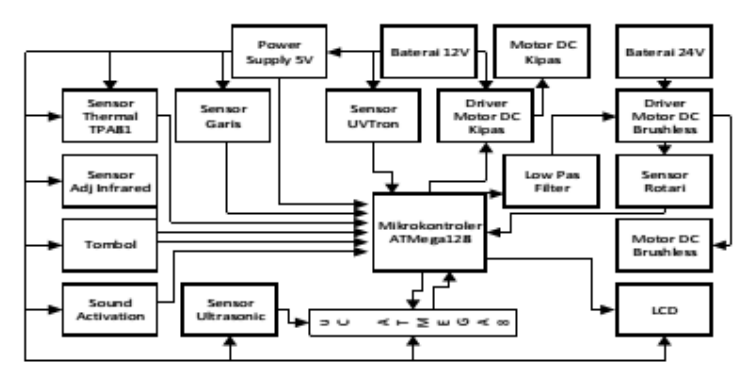

Gambar 6 diagram blok sistem robot

\subsection{Mekanik Robot}

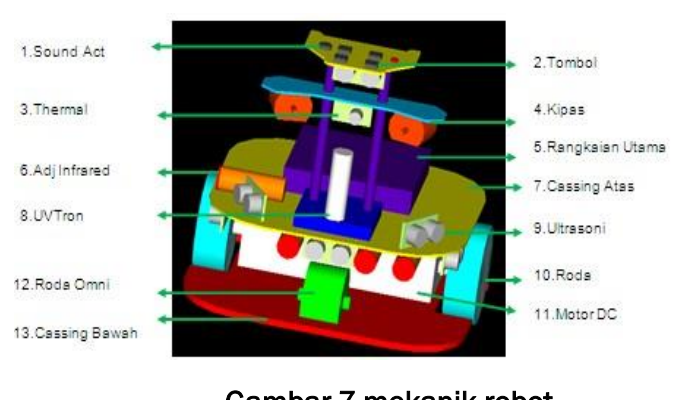

Gambar 7 mekanik robot

Untuk masing - masing komponen seperti yang dijelaskan dalam tabel berikut :

Tabel 1 penjelasan mekanik robot

\begin{tabular}{|c|l|l|}
\hline No & Keterangan & Fungsi \\
\hline 1 & Sound Act & $\begin{array}{l}\text { Menjalankan robot } \\
\text { menggunakan mode } \\
\text { suara alarm }\end{array}$ \\
\hline 2 & Tombol & $\begin{array}{l}\text { Menjalankan dan } \\
\text { mematikan robot } \\
\text { menggonakan mode } \\
\text { tombol }\end{array}$ \\
\hline 3 & Thermal TPA81 & $\begin{array}{l}\text { Mencari titik api dalam } \\
\text { ruangan }\end{array}$ \\
\hline 4 & Kipas & Mematikan lilin \\
\hline 5 & Rangkaian & Hardware pengendali \\
\hline 6 & Adj Infrared & $\begin{array}{l}\text { Sensor pengindra boneka } \\
\text { dan dinding }\end{array}$ \\
\hline 7 & Cassing atas & $\begin{array}{l}\text { Penampang robot bagian } \\
\text { atas }\end{array}$ \\
\hline 8 & UVTron & $\begin{array}{l}\text { Pendeteksi ada tidaknya } \\
\text { api pada ruangan }\end{array}$ \\
\hline 9 & $\begin{array}{l}\text { Ultrasonic } \\
\text { SRF04 }\end{array}$ & Sensor jarak \\
\hline 10 & Roda & Roda robot \\
\hline 11 & $\begin{array}{l}\text { Motor DC } \\
\text { Brushless }\end{array}$ & Aktuator penggerak \\
\hline 12 & Roda omni & Roda bagian depan \\
\hline 13 & Cassing Bawah & Penampang bawah robot \\
\hline
\end{tabular}

\subsection{Fuzzy Logic}

\section{Proses Fuzzifikasi}

Setelah mendapatkan informasi jarak setiap sensor yang dikirim oleh mikrokontroler slave, maka langkah selanjutnya adalah proses fuzzyfikasi. Langkah pertama dalam proses fuzzyfikasi adalah membuat membership function untuk setiap masukan jarak dari sensor depan, sensor pojok dan sensor kanan robot maupun output berupa PWM untuk motor kanan dan motor kiri. Untuk masing - masing sensor mempunyai tiga buah membership function yang nantinya akan menjadi masukan berupa variable linguistic untuk proses selanjutnya. Adapun membership function setiap sensor sebagai berikut

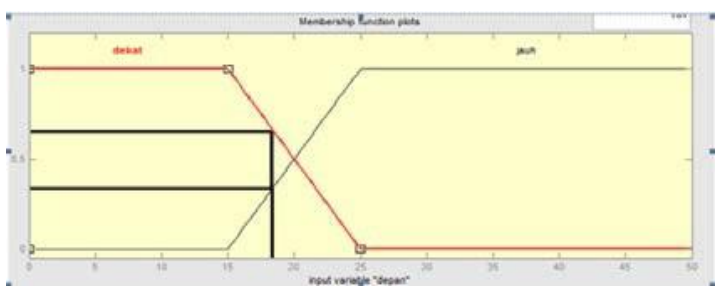

Gambar 8 membership function sensor depan

Adapun contoh membership function dari sensor depan dengan pembacaan jarak sebesar 18 sebagai berikut:

$$
\begin{aligned}
\mu \text { Fdekat[18] } & =(25-18) /(25-15) \\
& =7 / 10 \\
& =0.7 \\
\mu \text { Fjauh[18] } & =(18-15) /(25-15) \\
& =3 / 10 \\
& =0.3
\end{aligned}
$$

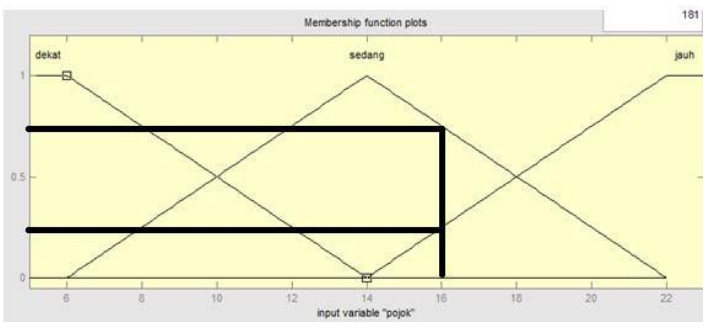

Gambar 9 member function sensor pojok

Adapun contoh membership function dari sensor pojok dengan pembacaan jarak sebesar 16 sebagai berikut:

$$
\begin{aligned}
\mu \text { Csedang[16] } & =(22-16) /(22-14) \\
& =6 / 8
\end{aligned}
$$




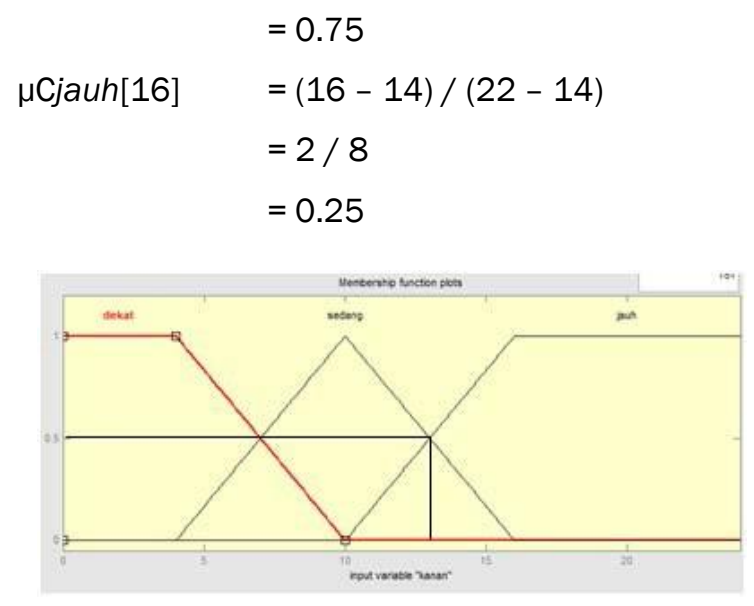

Gambar 10 member function sensor kanan

Adapun contoh membership function dari sensor kanan dengan pembacaan jarak sebesar 13 sebagai berikut:

$$
\begin{aligned}
\mu R s e d a n g[13] & =(16-13) /(16-10) \\
& =3 / 6 \\
& =0.5 \\
\mu \text { Rjauh[13] } & =(13-10) /(16-10) \\
& =3 / 6 \\
& =0.5
\end{aligned}
$$

\section{Evaluasi Rule}

Dalam evaluasi rule terjadi pengolahan data input fuzzyfikasi dengan hasil keluaran yang dikehendaki dengan aturan - aturan tertentu. Dari aturan - aturan yang dibentuk inilah yang nantinya akan menentukan respon dari sistem terhadap berbagai kondisi gangguan yang terjadi pada sistem yang akan dibuat. Langkah berikutnya adalah mencari derajat kebenaran untuk setiap aturan. Dikarenakan sistem terdiri dari beberapa aturan, maka inferensi diperoleh dari kumpulan dan kolerasi antar aturan. Kolerasi antar aturan dihubungkan dengan logika AND, dengan mengasumsikan bahwa nilai terkecil dari kolerasi tersebut yang akan dijadikan derajat kebenaran.

Dari kumpulan derajat kebenaran inilah yang nantinya akan diambil nilai maximal sebagai nilai konsekuen. Metode ini sering disebut dengan metode inferensi MIN-MAX, dikarenakan

\begin{tabular}{|c|c|c|c|c|}
\hline No & $\begin{array}{l}\text { Ultra } \\
\text { Pojok }\end{array}$ & $\begin{array}{l}\text { Ultra } \\
\text { Kana }\end{array}$ & $\begin{array}{c}\text { Ultra } \\
\text { Depan }\end{array}$ & PWM Kiri \\
\hline 1 & dekat & dekat & iauh & Asak Cenat \\
\hline 2 & dekat & sedang & iauh & cenat \\
\hline 3 & dekat & iawh & iauh & Asak Cenat \\
\hline 4 & sedang & dekat & iauh & cenat \\
\hline 5 & sedang & sedang & iauh & Arak Cenat \\
\hline 6 & sedang & iawh & iauh & agak nelan \\
\hline 7 & iauh & dekat & iauh & aøak cenat \\
\hline 8 & iauh & sedang & & agak nelan \\
\hline 9 & iauh & iauh & iauh & agak nelan \\
\hline 10 & dekat & dekat & dekat & sedano \\
\hline 11 & dekat & sedano & dekat & sedano \\
\hline 12 & dekat & iauh & dekat & sedang \\
\hline 13 & sedang & dekat & dekat & Arak Cenat \\
\hline 14 & sedang & sedang & dekat & sedang \\
\hline 15 & sedang & iauh & dekat & nelan \\
\hline 16 & iauh & dekat & dekat & sedano \\
\hline 17 & iawh & sedang & dekat & nelan \\
\hline 18 & iauh & iauh & dekat & nelan \\
\hline
\end{tabular}
mengambil nilai terkecil dari derajat kebenaran antaseden dan mengambil nilai terbesar dari

\begin{tabular}{|c|c|c|c|c|}
\hline No & $\begin{array}{l}\text { Ultra } \\
\text { Pojok }\end{array}$ & $\begin{array}{l}\text { Ultra } \\
\text { Kana } \\
\end{array}$ & $\begin{array}{c}\text { Ultra } \\
\text { Depan }\end{array}$ & PWM Kiri \\
\hline 1 & dekat & dekat & iauh & cenat \\
\hline 2 & dekat & sedang & ــ & cenat \\
\hline 3 & dekat & iauh & iauh & Arak cenat \\
\hline 4 & sedang & dekat & & Arak cenat \\
\hline 5 & sedang & sedang & & Asak cenat \\
\hline 6 & sedang & & & aøak nelan \\
\hline 7 & iauh & dekat & iauh & aøak nelan \\
\hline 8 & iauh & sedang & iauh & aøak nelan \\
\hline 9 & jawh & iauh & نـ & agak nelan \\
\hline 10 & dekat & dekat & dekat & Asak cenat \\
\hline 11 & dekat & sedang & dekat & sedang \\
\hline 12 & dekat & طسلـ & dekat & sedang \\
\hline 13 & sedang & dekat & dekat & sedang \\
\hline 14 & sedang & sedang & dekat & sedang \\
\hline 15 & sedang & iauh & dekat & nelan \\
\hline 16 & iauh & dekat & dekat & nelan \\
\hline 17 & jauh & sedang & dekat & nelan \\
\hline 18 & iauh & iauh & dekat & Delan \\
\hline
\end{tabular}
kumpulan derajat kebenaran sebagai konsekuen. Adapun evaluasi rule sebagai berikut:
Tabel 2 Evaluasi rule kanan

Tabel 3 Evaluasi rule kiri

Dari evaluasi rule yang sudah ada maka dapat diketahui setiap sekali siklus pembacaan sensor terjadi 8 buah aturan untuk motor kanan dan 8 buah aturan untuk motor kiri yang saling berkaitan, adapun aturan sebagai berikut: 
Tabel 4 Hasil pembacaan evaluasi rule kanan

\begin{tabular}{|c|c|c|c|c|}
\hline No & $\begin{array}{c}\text { Ultra } \\
\text { Pojok }\end{array}$ & $\begin{array}{c}\text { Ultra } \\
\text { Kana }\end{array}$ & $\begin{array}{c}\text { Ultra } \\
\text { Depan }\end{array}$ & PWM Kiri \\
\hline 1 & sedang & sedang & iauh & Agak Cenat \\
\hline 2 & sedang & iauh & iauh & agak belan \\
\hline 3 & iauh & sedang & iauh & agak nelan \\
\hline 4 & iauh & iauh & iauh & asak nelan \\
\hline 5 & sedang & sedang & dekat & sedang \\
\hline 6 & sedang & iauh & dekat & nelan \\
\hline 7 & iauh & sedang & dekat & nelan \\
\hline 8 & iauh & iauh & dekat & nelan \\
\hline
\end{tabular}

Tabel 5 Hasil pembacaan evaluasi rule kiri

\begin{tabular}{|c|c|c|c|c|}
\hline No & $\begin{array}{c}\text { Ultra } \\
\text { Pojok }\end{array}$ & $\begin{array}{c}\text { Ultra } \\
\text { Kana }\end{array}$ & $\begin{array}{c}\text { Ultra } \\
\text { Depan }\end{array}$ & PWM Kiri \\
\hline 1 & sedanø & sedang & iauh & Agak cenat \\
\hline 2 & sedanø & iauh & iauh & agak nelan \\
\hline 3 & iauh & sedang & iauh & agak nelan \\
\hline 4 & iauh & iauh & iauh & agak nelan \\
\hline 5 & sedang & sedang & dekat & sedang \\
\hline 6 & sedanø & iauh & dekat & nelan \\
\hline 7 & iauh & sedang & dekat & nelan \\
\hline 8 & iauh & iauh & dekat & nelan \\
\hline
\end{tabular}

Adapun contoh dari evaluasirule dengan menggunakan metode min-max sebagai berikut:

- $\alpha$ Predikat1 $=\mu$ Csedang $n \mu F s e d a n g ~ n \mu R j a u h$

$=\min (0.75,0.5,0.3)$

$=0.3$

Zkiri1 $=70$

Zkanan1= 100

- $\alpha$ Predikat2 $=\mu$ Csedang $n \mu F j a u h n \mu$ Rjauh

$=\min (0.75,0.5,0.3)$

$=0.3$

Zkiri2 $=100$

Zkanan2 $=70$

- $\alpha$ Predikat3 $\quad=\mu$ Cjauh $n \mu F s e d a n g ~ n ~ \mu R j a u h$

$=\min (0.25,0.5,0.3)$

$=0.25$

Zkiri3 = 100

Zkanan3= 70

- $\alpha$ Predikat4 $\quad=\mu$ Cjauh $n \mu F j a u h n ~ \mu R j a u h$

$=\min (0.25,0.5,0.3$

$=0.25$
Zkiri4 = 100

Zkanan4= 70

- $\alpha$ Predikat5 $\quad=\mu$ Csedang $n \mu$ Fsedang $n$ $\mu$ Rdekat

$$
\begin{aligned}
& =\min (0.75,0.5,0.7) \\
& =0.5 \\
\text { Zkiri5 } & =90
\end{aligned}
$$

Zkanan5 $=90$

- $\alpha$ Predikat6 $\quad=\mu$ Csedang $n \mu F j a u h n \mu$ Rdekat

$$
=\min (0.75,0.5,0.7)
$$$$
=0.5
$$

$$
\text { Zkiri6 }=110
$$

Zkanan6 $=60$

- $\alpha$ Predikat7 $\quad=\mu$ Cjauh $n \mu$ Fsedang $n \mu$ Rdekat

$=\min (0.25,0.5,0.7)$

$=0.25$

Zkiri7 = 110

Zkanan7 $=60$

- $\alpha$ Predikat8 $\quad=\mu$ Cjauh $n \mu$ Fjauh $n \mu$ Rdekat

$=\min (0.25,0.5,0.7)$

$=0.25$

Zkiri8 $=110$

Zkanan8 $=60$

Setelah nilai linguistik keluaran telah mendapatkan nilai derajat keanggotaan, maka pada nilai linguistik keluaran yang sejenis dicari nilai derajat keanggotaan yang maksimum untuk digunakan dalam pengolahan data selanjutnya, yakni defuzzifikasi.

- Motor kiri

Cepat $=0$

Agak Cepat $\quad=\alpha$ Predikat 1

$$
=0.3
$$

Sedang $=\alpha$ Predikat5

$$
=0.5
$$

Agak Pelan $=\max (\alpha$ Predikat2, $\alpha$ Predikat3, aPredikat4)

$$
\begin{aligned}
& =\max (0.3,0.25,0.25) \\
& =0.25
\end{aligned}
$$

Pelan $=\max (\alpha$ Predikat $6, \alpha$ Predikat 7 , aPredikat8) 


$$
\begin{aligned}
& =\max (0.5,0.25,0.25) \\
& =0.5
\end{aligned}
$$

- Motor kanan

$$
\begin{aligned}
& \begin{array}{ll}
\text { Cepat }=0 & \\
\text { Agak Cepat } & =0.3 \\
&
\end{array} \\
& \begin{aligned}
\text { Sedang } & =\alpha \text { Predikat } 5 \\
& =0.5
\end{aligned}
\end{aligned}
$$

Agak Pelan $=\max (\alpha$ Predikat2, $\alpha$ Predikat3, $\alpha$ Predikat4)

$$
\begin{aligned}
& =\max (0.3,0.25,0.25) \\
& =0.25
\end{aligned}
$$

Pelan $=\max (\alpha$ Predikat $6, \quad \alpha$ Predikat 7 , $\alpha$ Predikat8)

$$
\begin{aligned}
& =\max (0.5,0.25,0.25) \\
& =0.5
\end{aligned}
$$

\section{Defuzzyfikasi}

Dari keluaran evaluasi rule terdapat dua buah output yaitu berupa nilai evaluasi rule motor kanan dan nilai evaluasi rule kiri. Dikarenakan ada dua keluaran maka proses defuzzyfikasi juga dilakukan dua kali, yaitu untuk motor kanan dan motor kiri. Metode yang digunakan untuk proses ini adalah defuzzyfikasi model sugeno orde satu. Nilai konsekuen untuk evaluasi rule bukan berbentuk fuzzy lagi melainkan berbentuk konstanta atau persamaan linear

$$
\text { Final Output }=\frac{\sum_{i=1}^{N} w_{i} z_{i}}{\sum_{i=1}^{N} W_{i}}
$$

Adapun contoh dari pengambilan hasil evaluasi rule dengan menggunakan metode min - max untuk defuzzyfikasi seperti berikut:

Pwm Left $=($ motor kiri cepat $*$ cepat $)+($ motor kiri agak cepat *agak cepat) + (motor kiri sedang * sedang $)+$ (motor kiri ag pelan * agak pelan $)+$ (motor kiri pelan * pelan) / (motor kiri cepat + motor kiri agak cepat + motor kiri sedang + motor kiri agak pelan + motor kiri pelan)

$$
\begin{aligned}
& =(0 * 60)+(0.3 * 70)+(0.5 * 90)+ \\
& (0.25 * 100)+(0.5 * 110) /(0+0.3 \\
& +0.5+0.25+0.5) \\
& =(0+21+45+25+55) /(1.55)
\end{aligned}
$$

$=94.19$

Pwm Right $=$ (motor kanan cepat * cepat $)+($ motor kanan agak cepat * agak cepat) + (motor kanan sedang * sedang) + (motor kanan agak pelan * agak pelan) + (motor kanan pelan * pelan)/ (motor kanan cepat + motor kanan agak cepat + motor kanan sedang + motor kanan agak pelan + motor kanan pelan)

$$
\begin{aligned}
& =(0 * 110)+(0.3 * 100)+(0.5 * 90) \\
& +(0.25 * 70)+(0.5 * 60) /(0+0.3 \\
& +0.5+0.25+0.5) \\
& =(0+30+45+17.5+30) /(1.55) \\
& =79.03
\end{aligned}
$$

Dari sinilah akan dihasilkan keluaran berupa konstanta nilai PWM untuk mengatur kecepatan motor kanan dan juga PWM untuk motor kiri. Setelah mendapatkan nilai PWM kanan dan nilai PWM kiri, selanjutnya mencoba menjalankan robot. Amati respon robot terhadap obstacle atau respon pembacaan dinding, sudah sesuai atau belum. Ketika robot masih mengalami osilasi maka harus mengubah rule ataupun kombinasi nilai PWM yang kurang tepat pada defuzzyfikasi yang telah dibuat sampai robot berjalan menyusuri dinding dengan bagus. Cara coba - coba ini dilakukan karena setiap robot memiliki kondisi yang berbeda - beda baik dalam program, rangkaian dan juga mekanik.

\section{Kesimpulan}

Berdasarkan perancangan serta pengujian yang telah dipaparkan pada bab sebelumnya, maka dapat diperoleh kesimpulan yaitu:

1. Untuk mendapat respon yang baik pada sistem fuzzy logic kontroler dapat dilakukan tuning evaluasi rules serta membership function.

2. Penggunaan algoritma right wall following pada saat robot bernavigasi menggunakan metode fuzzy logic berhasil membuat robot menemukan sumber api dan memadamkannya dengan prosentase keberhasilan $80 \%$.

3. Pada hasil pengujian yang telah dilakukan pada bab sebelumnya, dapat diketahui kecepatan kontroler fuzzy dalam bernavigasi sebesar 36.9 detik dengan rata - rata pinalti sebanyak 3 kali, sedangkan kontroller lain sebesar 41.1 detik dengan rata - rata pinalti sebesar 7 kali pada saat bernavigasi tanpa 
mematikan titik api .Selisih kedua kontroler sebesar 5 detik dan selisih pinalti sebanyak 4 kali. Sehingga dapat dikatakan kontroler fuzzy lebih cepat dan tepat dibandingkan dengan kontroler yang lain.

\section{Daftar Pustaka}

[1] Sri Kusumadewi,"Artificial Intelligence" Graha IImu, 2003.

[2] Arwani, dkk. 2005. "Model Pembobotan Ultrasonic Rangefinder Sebagai Input Kontrol Fuzzy Untuk Obstacle Avoidance Pada Robot Cerdas PemadamApi". Politeknik Negeri Surabaya - ITS. Surabaya.
[3] Samsul, Fahmi 12. "Rancang Bangun Perangkat Lunak Alat Pendeteksi Dini dan Penanggulangan Kebocoran Gas LPG Berbasis Mikrokontroler ATMega 8535" jurusan Sistem Komputer. Sekolah Tinggi

[4] Buku Panduan KRPAI 2014.

[5] Rully Muhammad lqbal,dkk. 2012. "Implementasi Sistem Navigasi Behavior Based Robotic dan Kontroler Fuzzy pada Manuver Robot Cerdas Pemadam Api” Jurnal Teknik Pomits, Vol. 1 No. 1 ITS.

[6] Nuryono Satya Widodo, "Penerapan MultiMikrokontroler Pada Model Robot Mobil Berbasis Logika Fuzi". Telekomnika Vol 13 No 1, Universitas Ahmad Dahlan. (UAD) Yogyakarta. 